\title{
Rhododendron album Blume inhibits iNOS and COX-2 expression in LPS-stimulated RAW264.7 cells through the downregulation of NF-кB signaling
}

\author{
JI-WON PARK ${ }^{1,2}$, OK-KYOUNG KWON ${ }^{1,3}$, JUNG-HEE KIM ${ }^{1}$, SEI-RYANG OH ${ }^{1}$, \\ JAE-HONG KIM ${ }^{2}$, JIN-HYUB PAIK ${ }^{4}$, BAMBANG MARWOTO ${ }^{5}$, RIFATUL WIDJHATI ${ }^{5}$, \\ FIFIT JUNIARTI $^{5}$, DODDY IRAWAN ${ }^{5}$ and KYUNG-SEOP AHN ${ }^{1}$ \\ ${ }^{1}$ Natural Medicine Research Center, Korea Research Institute of Bioscience and Biotechnology, \\ Chungbuk 363-883; ${ }^{2}$ College of Life Sciences and Biotechnology, Korea University, Seoul 136-701; \\ ${ }^{3}$ Department of Toxicology, College of Pharmacy, Chungnam National University, Daejeon 305-764; \\ ${ }^{4}$ International Biological Material Research Center, Research Institute of Bioscience and Biotechnology, \\ Daejeon 305-806, Republic of Korea; ${ }^{5}$ Center of Pharmaceutical and Medical Technology, \\ The Agency for the Assessment and Application of Technology (BPPT), \\ Kawasan Puspiptek Serpong, Tangerang, Banten 15314, Indonesia
}

Received April 25, 2014; Accepted February 2, 2015

DOI: 10.3892/ijmm.2015.2107

\begin{abstract}
Rhododendron album Blume (RA) has traditionally been used as an herbal medicine and is considered to have anti-inflammatory properties. In the present study, we screened RA extracts with anti-inflammatory properties. The biological effects of an RA methanol extract (RAME) on inflammation were investigated in lipopolysaccharide (LPS)-stimulated mouse RAW264.7 cells. We investigated the effects of RAME on the production of nitric oxide (NO) and prostaglandin E2 $\left(\mathrm{PGE}_{2}\right)$ in LPS-stimulated RAW264.7 cells. To explore the anti-inflammatory mechanisms of RAME, we measured the mRNA and protein expression of pro-inflammatory mediators induced by RAME in the LPS-stimulated RAW264.7 cells by RT-PCR and western blot analysis, respectively. RAME significantly inhibited the production of $\mathrm{NO}, \mathrm{PGE}_{2}$, interleukin (IL)-6, IL-1 $\beta$ and tumor necrosis factor (TNF)- $\alpha$ in the LPS-stimulated RAW264.7 cells. It also suppressed the mRNA and protein expression of inducible NO synthase (iNOS), cyclooxygenase-2 (COX-2) and mitogenactivated protein kinases (MAPKs) with a concomitant decrease in the nuclear translocation of nuclear factor- $\kappa \mathrm{B}(\mathrm{NF}-\kappa \mathrm{B})$ in the LPS-stimulated RAW264.7 cells. These results indicate that RAME inhibits LPS-induced inflammatory responses. These effects were considered to be strongly associated with
\end{abstract}

Correspondence to: Dr Kyung-Seop Ahn, Natural Medicine Research Center, Korea Research Institute of Bioscience and Biotechnology, 30 Yeongudanji-ro, Ochang-eup, Cheongwon-gun, Chungbuk 363-883, Republic of Korea

E-mail: ksahn@kribb.re.kr

Key words: Rhododendron album Blume, inflammation, lipopolysaccharide, mitogen-activated protein kinases, nuclear factor- $\mathrm{kB}$ the suppression of NF- $\mathrm{NB}$ activation. We therefore suggest that RAME may be prove to be an effective therapeutic agent for the treatment of inflammatory diseases.

\section{Introduction}

Inflammation is a central feature of a number of pathophysiological conditions in response to tissue injury and in the host defense against invading microbes. Pro-inflammatory cells, mainly activated macrophages, mediate most of the cellular and molecular pathophysiology of inflammation by producing cytokines and other pro-inflammatory molecules, including prostaglandins (PGs), enzymes and free radicals, such as nitric oxide (NO) $(1,2)$. NO, which is a strong stimulus, has been implicated in the pathogenesis of a variety of inflammatory diseases and is synthesized from L-arginine by inducible NO synthase (iNOS) (3). Moreover, cyclooxygenase-2 (COX-2) is also involved in the pathology of chronic inflammation. COX-2 is an inducible enzyme and is induced by lipopolysaccharides (LPS) and several cytokines (4). Thus, iNOS and COX-2 are plausible targets for the prevention or treatment of chronic inflammatory disorders, and the development of effective iNOS and COX-2 inhibitors represents a major advance in the treatment of inflammatory processes $(5,6)$.

The nuclear factor- $\kappa \mathrm{B}(\mathrm{NF}-\kappa \mathrm{B})$ and mitogen-activated protein kinase (MAPK) signaling pathways are key regulators of the expression of inflammatory mediators, including COX-2 and iNOS $(7,8)$. In unstimulated cells, the dimeric form of NF- $\mathrm{NB}$ is trapped in the cytoplasm by physical association with an inhibitory protein, I $\mathrm{B}(9,10)$. A number of stimuli, including LPS, cytokines and viruses, activate $\mathrm{NF}-\kappa \mathrm{B}$ through several signal transduction pathways, leading to the phosphorylation of $\mathrm{I} \kappa \mathrm{B}$. The activation of MAPKs contributes to the production of inflammatory mediators, such as COX-2 
and iNOS in activated macrophages (11), and specific MAPK inhibitors suppress COX-2 and iNOS expression $(12,13)$.

Rhododendron album Blume (RA) is a species of plant that belongs to the Ericaceae family and it is endemic to Indonesia. It is mostly found in the increasingly smaller high elevation forests throughout West and Central Java. RA is grown widely in nurseries throughout the world, particularly in the United States. RA, along with many other variations and hybrids, is a popular plant in the landscaping industry and is used for a variety of decorations, including wedding and special occasion bouquets, corsages and other floral arrangements. However, to the best of our knowledge, there are no data available in the literature on the anti-inflammatory activity of this plant. Therefore, the aim of the present study was to evaluate the anti-inflammatory activity of a methanol extract of this plant.

As part of our continuing search to identify anti-inflammatory compounds from natural products, we identified RA as a potent inhibitor of iNOS and COX-2 expression in LPS-stimulated RAW264.7 cells. To the best of our knowledge, in this study, we demonstrate for the first time that RA is a novel natural anti-inflammatory compound that blocks the LPS-induced activation of the NF- $\kappa \mathrm{B}$ and MAPK pathways.

\section{Materials and methods}

Preparation of the RA extract. Plant material was collected from Cantigi, Indonesia in 2008. The plant was identified by the botanist, Agung Sedayu. A voucher specimen (KRIB 0019989) has been deposited in the herbarium of the Korea Research Institute of Bioscience and Biotechnology. The RA plant material was treated with methanol $(\mathrm{MeOH})$ and sonicated several times at room temperature for 3 days to produce an extract.

Cell culture. RAW264.7 cells [American Type Culture Collection (ATCC); Manassas, VA, USA], a mouse monocyte/ macrophage cell line, were maintained in a $95 \%$ air, $5 \% \mathrm{CO}_{2}$ atmosphere in Dulbecco's modified Eagle's medium (DMEM; Gibco-BRL, Grand Island, NY, USA) supplemented with $10 \%$ heat-inactivated fetal bovine serum (FBS; HyClone, Logan, UT, USA) and 1\% antibiotic-antimycotic (Invitrogen, Grand Island, NY, USA). The RAW264.7 cells were maintained by weekly passage, and the cells were utilized for experimentation at $60-80 \%$ confluence. Following pre-incubation of the RAW264.7 cells for $4 \mathrm{~h}, 0-40 \mu \mathrm{g} / \mathrm{ml}$ of the extract were added. Bay 11-7082 was used to inhibit the NF- $\kappa$ B pathway. Bay 11-7082, also known as (E)-3-(4-methylphenylsulfonyl)2-propenenenitrile, has a molecular weight of $207.25 \mathrm{kDa}$ and was provided at $\geq 98 \%$ purity (HPLC). It is an irreversible inhibitor of $\mathrm{I} \kappa \mathrm{B} \alpha$ phosphorylation, which increases the stabilization of $\mathrm{I} \kappa \mathrm{B} \alpha$ and specifically blocks NF- $\kappa \mathrm{B}$ signaling (14).

Cell viability. Cell proliferation was measured by means of a 3-(4,5-dimethylthiazol-2-yl)-2,5-diphenyltetrazolium bromide (MTT; Amresco, Solon, OH, USA) assay, as previously described (31). To calculate the true values, the background levels of the RA methanol extract (RAME) were obtained by incubating the extract with MTT solution alone and were then subtracted from the experimental values.
NO assay. The RAW264.7 cells were plated at a density of $2.5 \times 10^{5}$ cells $/ \mathrm{ml}$ in 96-well plates and then incubated with or without LPS $(0.5 \mu \mathrm{g} / \mathrm{ml})$ in the absence or presence of various concentrations of RAME for $24 \mathrm{~h}$. The NO accumulation in the supernatant was assessed by a Griess reaction. Each $100 \mu \mathrm{l}$ of the culture supernatant was mixed with an equal volume of Griess reagent [0.1\% N-(1-naphthyl)-ethylenediamine, $1 \%$ sulfanilamide in $5 \%$ phosphoric acid] and incubated at room temperature for $10 \mathrm{~min}$. The absorbance was measured at $540 \mathrm{~nm}$ using a microplate reader, and a series of known concentrations of sodium nitrite was used as a standard.

Prostaglandin E2 (PGE 2 ) assay. The $\mathrm{PGE}_{2}$ concentration in the supernatant was determined using a commercially available PGE $_{2}$ ELISA kit (Cayman Chemical Co., Ann Arbor, MI, USA), according to the manufacturer's instructions. The $\mathrm{PGE}_{2}$ concentrations were determined by measuring the absorbance at $405 \mathrm{~nm}$.

Reverse transcription (RT)-PCR. RT-PCR was performed for the detection of the mRNA expression of iNOS, COX-2, interleukin (IL)-6, IL-1 $\beta$, tumor necrosis factor (TNF)- $\alpha$ and $\beta$-actin. Briefly, following stimulation of the RAW264.7 cells with LPS $(0.5 \mu \mathrm{g} / \mathrm{ml})$ of for $6 \mathrm{~h}$, total RNA was isolated using TRIzol $^{\mathrm{TM}}$ reagent (Invitrogen) as recommended by the manufacturer. Subsequently, a reverse transcription reaction was carried out using a kit for producing cDNA (Qiagen $\mathrm{GmbH}$, Hilden, Germany). PCR was carried out using specific forward and reverse primers and a premix according to the manufacturer's instructions (Bioneer Corp., Daejeon, Korea). The following conditions were used for each PCR reaction: $94^{\circ} \mathrm{C}$ for $5 \mathrm{~min}(1 \mathrm{cycle}) ; 94^{\circ} \mathrm{C}$ for $30 \mathrm{sec}, 60^{\circ} \mathrm{C}$ for $30 \mathrm{sec}$, and $72^{\circ} \mathrm{C}$ for $45 \mathrm{sec}$ (for 30 cycles); and a final extension phase at $72^{\circ} \mathrm{C}$ for $10 \mathrm{~min}$. The primer sequences for the analysis of mRNA expresion were as follows: iNOS, 5'-CAA GAG TTT GAC CAG AGG ACC-3' (sense) and 5'-TGG AAC CAC TCG TAC TTG GGA-3' (antisense); COX-2, 5'-GAA GTC TTT GGT CTG GTG CCT G-3' (sense) and 5'-GTC TGC TGG TTT GGA ATA GTT GC-3' (antisense); IL-1 $\beta$, 5'-GTG TCT TTC CCG TGG ACC TT-3' (sense) and 5'-TCG TTG CTT GGT TCT CCT TG-3' (antisense); IL-6, 5'-AAC GAT GAT GCA CTT GCA GA-3' (sense) and 5'-GAG CAT TGG AAA TTG GGG TA-3' (antisense); TNF- $\alpha$ were 5'-CAT CTT CTC AAA ATT CGA GTG ACA A-3' (sense) and 5'-TGG GAG TAG ACA AGG TAC AAC CC-3' (antisense); and $\beta$-actin, 5'-TGT TTG AGA CCT TCA ACA CC-3' (sense) and 5'-CGC TCA TTG CCG ATA GTG AT-3' (antisense). $\beta$-actin was included as an internal, housekeeping control gene. The reaction products were separated by electrophoresis on a $1.5 \%$ agarose gel, stained with ethidium bromide (EtBr) and visualized by UV transillumination. Images were captured using an Olympus C-4000 Zoom camera system (Olympus America Inc., Melville, NY, USA).

Western blot analysis. Total protein $(30 \mu \mathrm{g})$ was separated on a $10 \%$ SDS polyacrylamide gel and transferred onto PVDF membranes (Millipore, Billerica, MA, USA). Each membrane was then incubated for $1 \mathrm{~h}$ in 5\% skim milk in TBS-T buffer (0.1 M Tris-HCl, pH 7.4, 0.9\% NaCl, 0.1\% Tween-20) to block non-specific binding and was then incubated with primary 

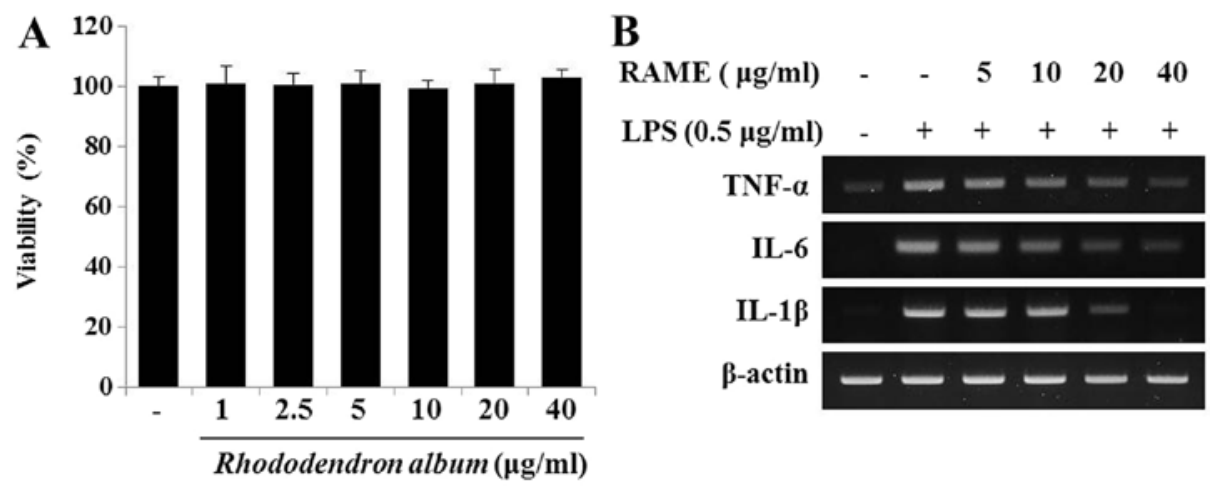

Figure 1. Rhododendron album Blume methanol extract (RAME) inhibits interleukin (IL)-6, IL-1 $\beta$ and tumor necrosis factor (TNF)- $\alpha$ production. (A) Effects of RAME on the viability of cells. RAW264.7 cells were incubated in the presence or absence of $0-40 \mu \mathrm{M}$ of RAME, and the cell viability was determined by MTT assay. The data are presented as the means \pm SEM of 3 independent experiments. (B) Cytokine expression was measured by RT-PCR in the cultured cells. The samples were analyzed according to the manufacturer's instructions (see Materials and methods). Data are presented as the means \pm SEM of 3 samples.

antibodies that recognized iNOS (Cat. no. ADI-905-431, 1:1,000; obtained from Enzo Life Sciences, Farmingdale, NY, USA), COX-2 (Cat. no. sc-1747, 1:1,000; Santa Cruz Biotechnology, Santa Cruz, CA, USA), $\beta$-actin (Cat. no. \#4967, 1:2,000; Cell Signaling Technology, Danvers, MA, USA), PARP (Cat. no. \#9542; Cell Signaling Technology), the total forms of extracellular signal-regulated kinase (ERK)2 (sc-154), p38 MAPK (sc-7149), c-Jun N-terminal kinase (JNK)1/3 (sc-474, 1:1,000; Santa Cruz Biotechnology), the phosphorylated forms of p38 MAPK (ADI-KAP-MA022) and JNK1/2 (KAP-SA011, 1:1,000; Enzo Life Sciences, Inc.) and the phosphorylated forms of ERK (\#9106, 1:1,000; Cell Signaling Technology). Each protein was detected using a chemiluminescence detection system according to the instructions of the manufacturer (ECL; Amersham, Berkshire, UK).

Immunocytochemistry. The RAW264.7 cells were cultured on Permanox plastic chamber slides (Nunc, Rochester, NY, USA) and fixed in ethanol at $4^{\circ} \mathrm{C}$ for $30 \mathrm{~min}$. The slides were washed 3 times with PBS and blocked with $3 \%(\mathrm{w} / \mathrm{v})$ BSA in PBS for a further $30 \mathrm{~min}$. Subsequently, the slides were incubated for $24 \mathrm{~h}$ at $4^{\circ} \mathrm{C}$ with anti-NF- $\mathrm{B}$ p65 subunit (rabbit polyclonal IgG, 1:500 dilution; Enzo Life Sciences, Inc.) antibodies. After washing to remove the excess primary antibody, the slides were further incubated with an anti-rabbit Alexa Fluor 488-conjugated secondary antibody (Santa Cruz Biotechnology) for $2 \mathrm{~h}$ at room temperature, washed with PBS, and mounted using ProLong Gold antifade reagent containing 4',6-diamidino2-phenylindole (DAPI) (Invitrogen) for $5 \mathrm{~min}$, prior to the localization and quantification of the nuclei. Subsequently, the slides were coverslipped and visualized under a confocal laser scanning microscope (LSM 510 m; Carl Zeiss AG, Jena, Germany). All the samples were photographed under the same exposure conditions, and the nuclei were quantified from the images obtained.

Statistical analysis. Values are expressed as the means \pm SEM of the sample size determinations. Statistical significance was determined using a two-tailed Student's t-test for independent means. The test results are reported as two-tailed P-values, where $\mathrm{P}<0.05$ was considered to indicate a statistically significant difference.

\section{Results}

Evaluation of the cytotoxicity of RAME on RAW264.7 cells. A prerequisite for studying the biological activity of RAME is to ensure that it does not have a detrimental effect on cell metabolism. To determine whether RAME affects cell viability, the RAW264.7 cells were incubated for $24 \mathrm{~h}$ with the extract at a wide range of concentrations $(0-40 \mu \mathrm{g} / \mathrm{ml})$ and cell viability was evaluated by MTT assay. There was no significant change in cell survival at concentrations of RAME of up to $40 \mu \mathrm{g} / \mathrm{ml}$ (Fig. 1A).

RAME decreases the release of pro-inflammatory cytokines in LPS-stimulated RAW264.7 cells. LPS stimulation induced an increase in the mRNA expression levels of TNF- $\alpha$, IL-6 and IL-1 $\beta$ in the RAW264.7 cells. By contrast, RAME significantly decreased the release of these mediators in a concentrationdependent manner (Fig. 1B).

RAME reduces the production of NO by suppressing iNOS expression in LPS-stimulated RAW264.7 cells. The unstimulated RAW264.7 cells secreted basal levels of NO, while LPS stimulation resulted in an increase in NO production. RAME significantly inhibited the LPS-induced production of NO in a concentration-dependent manner. At a concentration of $40 \mu \mathrm{g} / \mathrm{ml}$ RAME, NO production was significantly reduced, and the level of NO was very close to the basal levels (Fig. 2A). The LPS-stimulated RAW264.7 cells overexpressed iNOS mRNA, whereas this overexpression was suppressed by treatment with RAME (Fig. 2B). The results obtained for the protein expression of iNOS were consistent with those obtained for the mRNA expression. RAME inhibited the protein expression of iNOS in the RAW264.7 cells stimulated with LPS (Fig. 2C).

RAME decreases the production of $P G E_{2}$ by suppressing COX-2 expression in LPS-stimulated RAW264.7 cells. The unstimulated RAW264.7 cells secreted basal levels of $\mathrm{PGE}_{2}$, while LPS stimulation induced an increase in $\mathrm{PGE}_{2}$ production. RAME significantly decreased the LPS-induced production of $\mathrm{PGE}_{2}$ in a concentration-dependent manner (Fig. 3A). The LPS-stimulated RAW264.7 cells overexpressed COX-2 mRNA, whereas the LPS-stimulated RAW264.7 cells treated with RAME showed a decreased mRNA expression of 
A

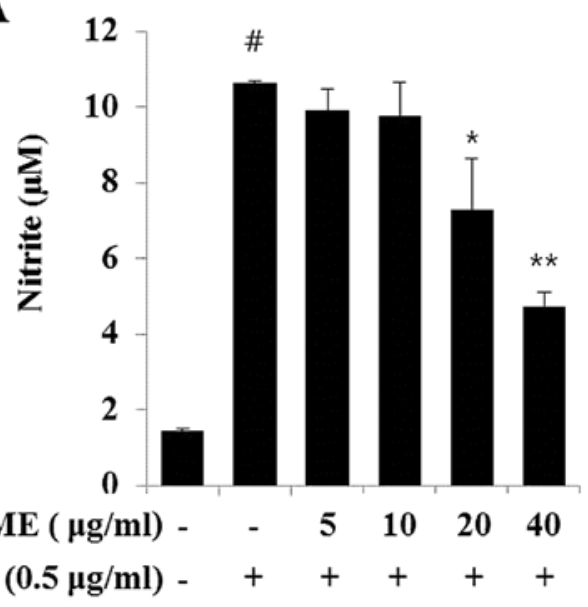

B $\operatorname{RAME}(\mu \mathrm{g} / \mathrm{ml})-\frac{1}{5} \quad$\begin{tabular}{llll}
\hline & 10 & 20 & 40
\end{tabular} $\operatorname{LPS}(0.5 \mu \mathrm{g} / \mathrm{ml})-+++++$

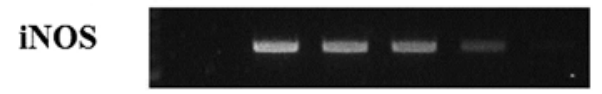

$\beta$-actin

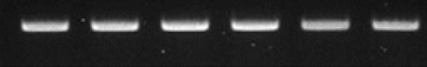

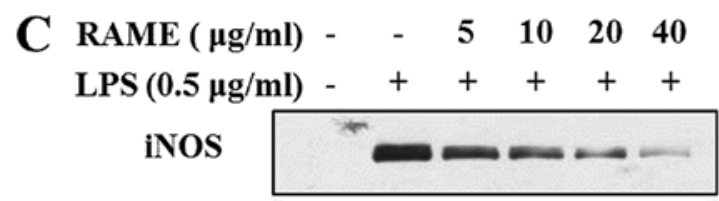

$\beta$-actin

Figure 2. Rhododendron album Blume methanol extract (RAME) inhibits lipopolysaccharide (LPS)-induced nitric oxide (NO) production and inducible NO synthase (iNOS) expression in RAW264.7 cells. (A) RAW264.7 cells were pre-treated with RAME (5, 10, $20 \mathrm{or} 40 \mu \mathrm{g} / \mathrm{ml}$ ) for $1 \mathrm{~h}$ and then stimulated with LPS $(0.5 \mu \mathrm{g} / \mathrm{ml})$. The culture medium was collected at $24 \mathrm{~h}$, and the NO concentrations were measured by Griess reaction. Three independent experiments were performed, and the data are presented as the means \pm SEM. ${ }^{*} \mathrm{P}<0.05$ and $^{* *} \mathrm{P}<0.01$ compared with the cells treated with LPS alone. ${ }^{*} \mathrm{P}<0.001$ significantly different from normal control group. (B) RAW264.7 cells were pre-treated with RAME for $1 \mathrm{~h}$ and stimulated with LPS for $6 \mathrm{~h}$. $\beta$-actin expression was used as an internal control for RT-PCR. (C) RAW264.7 cells were pre-treated with RAME for $1 \mathrm{~h}$ and stimulated with LPS for $24 \mathrm{~h}$. The cell lysates were obtained, and the iNOS protein levels were analyzed by western blot analysis. $\beta$-actin expression was used as an internal control for western blot analysis.
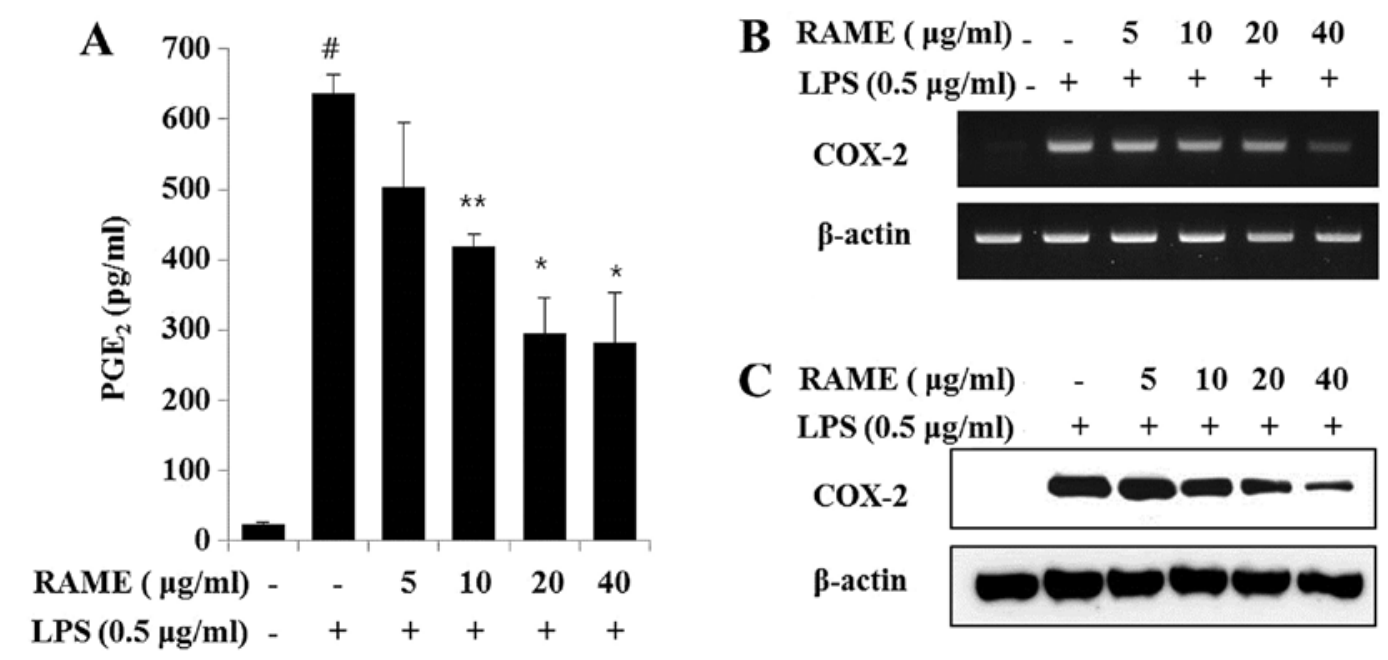

C RAME $(\mu \mathrm{g} / \mathrm{ml}) \quad-\quad 5 \quad 10 \quad 20 \quad 40$

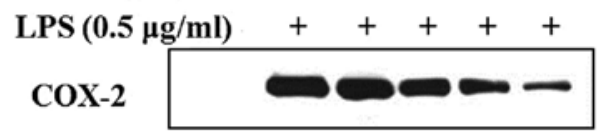

$\begin{array}{lllllll}\operatorname{RAME}(\mu \mathrm{g} / \mathrm{ml}) & - & - & 5 & 10 & 20 & 40 \\ \operatorname{LPS}(0.5 \mu \mathrm{g} / \mathrm{ml}) & - & + & + & + & + & +\end{array}$

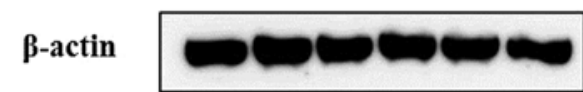

Figure 3. Rhododendron album Blume methanol extract (RAME) inhibits lipopolysaccharide (LPS)-induced PGE $_{2}$ production and cyclooxygenase-2 (COX-2) expression in RAW264.7 cells. (A) RAW264.7 cells were pre-treated with RAME $(5,10,20$ or $40 \mu \mathrm{g} / \mathrm{ml})$ for $1 \mathrm{~h}$, and then stimulated with LPS $(0.5 \mu \mathrm{g} / \mathrm{ml})$. The culture medium was collected at $24 \mathrm{~h}$, and the $\mathrm{PGE}_{2}$ concentrations were measured using an enzyme immunoassay. Three independent experiments were performed, and the data are presented as the means \pm SEM. ${ }^{*} \mathrm{P}<0.05$ and ${ }^{* *} \mathrm{P}<0.01$ compared with the cells treated with LPS alone. ${ }^{*} \mathrm{P}<0.001$ significantly different from normal control group. (B) RAW264.7 cells were pre-treated with RAME for $1 \mathrm{~h}$, and stimulated with LPS for $6 \mathrm{~h}$. $\beta$-actin expression was used as an internal control for RT-PCR. (C) RAW264.7 cells were pre-treated with RAME for $1 \mathrm{~h}$ and stimulated with LPS for $24 \mathrm{~h}$. $\beta$-actin expression was used as an internal control for western blot analysis.

COX-2 (Fig. 3B). The results obtained for the protein expression of COX-2 were consistent with those obtained for the mRNA expression. RAME inhibited the protein expression of COX-2 in the RAW264.7 cells stimulated with LPS (Fig. 3C).

Effects of RAME on the activation of MAPKs in LPS-stimulated RAW264.7 cells. Three MAPKs, ERK, p38 and JNK, are known to be activated by LPS. MAPKs play an important role in the transcriptional regulation of the LPS-induced expression of iNOS and COX-2 through the activation of the transcription factor, NF- $\kappa \mathrm{B}$ (15). As shown in Fig. 4, pre-treatment with
RAME markedly increased the phosphorylation of ERK1/2 and enhanced the phosphorylation of JNK and p38. These results indicate that the inhibitory effects of RAME on TNF- $\alpha$, IL-1 $\beta$, IL-6, NO and $\mathrm{PGE}_{2}$ expression may be mediated through the downstream MAPK pathway.

Effects of RAME on LPS-stimulated NF- $\kappa B$ transcriptional activity through the suppression and nuclear translocation of the p65 subunit in RAW264.7 cells. NF- $\kappa \mathrm{B}$ plays a pivotal role in the regulation of the expression of iNOS, COX-2 and inflammatory cytokines, such as TNF- $\alpha$, IL-1 $\beta$ and IL-6 (16). 


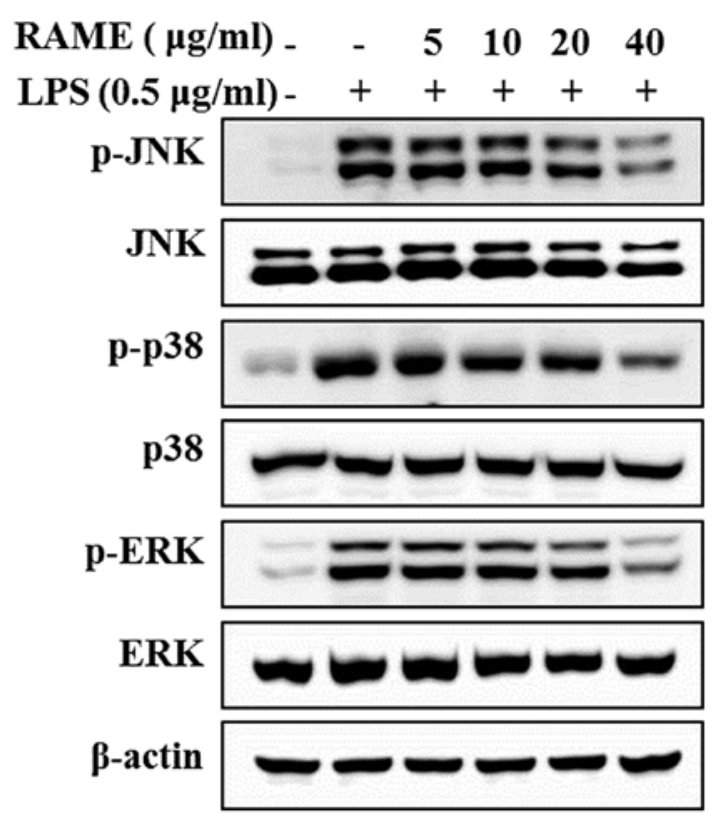

Figure 4. Rhododendron album Blume methanol extract (RAME) suppresses the phosphorylation of mitogen-activated protein kinase (MAPK)-associated molecules in lipopolysaccharide (LPS)-stimulated RAW264.7 cells. Cells were pre-incubated with RAME for $12 \mathrm{~h}$ and then incubated with LPS $(0.5 \mu \mathrm{g} / \mathrm{ml})$ for $20 \mathrm{~min}$. The total protein lysate was subjected to western blot analysis. The ratio of the immunointensity of p-ERK1/2, p-JNK and p-p38 was calculated Total ERK1/2, JNK and p38 (ERK1/2, JNK and p38) were used as a control for the amount of protein in the same samples. A representative blot of each experiment is shown with the densitometric analysis corresponding to the means \pm SEM of 3 independent experiments.

The activation of $\mathrm{NF}-\kappa \mathrm{B}$, an important transcription factor in the inflammatory response, occurs after phosphorylation. Our results revealed that RAME inhibited NF- $\kappa$ B phosphorylation which was induced following stimulation with LPS. We further investigated the effects of RAME on the activation of $\mathrm{NF}-\kappa \mathrm{B}$ by immunofluorescence. The LPS-induced translocation of the NF- $\mathrm{B}$ p65 subunit from the cytosol to the nucleus in the RAW264.7 cells (Fig. 5B) was inhibited by RAME. The NF- $\kappa \mathrm{B}$ protein levels significantly correlated with the reduced nuclear accumulation (Fig. 5A). Thus, our results suggest that RAME inhibits the translocation of the $\mathrm{NF}-\kappa \mathrm{B}$ p65 subunit through the regulation of a signal transduction mechanism related to $\mathrm{NF}-\kappa \mathrm{B}$ activation.

$R A M E$ and an inhibitor of I $\kappa B-\alpha$ phosphorylation (Bay 11-7082) inhibit both NO expression and the activation of $N F-\kappa B$ in LPS-stimulated RAW264.7 cells. RAME significantly suppressed the LPS-induced activation of NF- $\mathrm{BB}$ in the RAW264.7 cells, as shown by western blot analysis. Bay 11-7082 (Calbiochem/Merck, Darmstadt, Germany), a potential anti-inflammatory agent, is an irreversible inhibitor of cytokine-inducible $\mathrm{I} \kappa \mathrm{B}-\alpha$ phosphorylation $\left(\mathrm{IC}_{50}=10 \mu \mathrm{M}\right)(17)$. Bay 11-7082 markedly blocked the LPS-induced activation of NF- $\kappa \mathrm{B}$. As expected, RAME $(40 \mu \mathrm{g} / \mathrm{ml})$ inhibited the LPS-induced activation of NF- $\mathrm{B}$ (Fig. 6A). These results suggest that RAME reduces inflammation by inhibiting the LPS-induced activation of NF- $\kappa \mathrm{B}$ in RAW264.7 cells. In addition, RAME and Bay 11-7082 affected the expression of NO.
The inhibition of NO expression by each of the compounds was clearly evident (Fig. 6B).

\section{Discussion}

Herbal medicines are becoming increasingly attractive therapies for the treatment of various inflammatory disorders $(18,19)$. Herbal remedies have traditionally been used as medicines in several countries (20). In the present study, our results revealed that RAME significantly inhibited the produc-

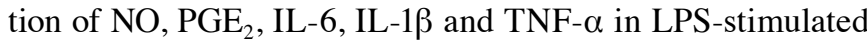
RAW264.7 cells. RAME suppressed the mRNA and protein expression of iNOS, COX-2 and MAPKs (p38 MAPK, JNK and ERK) with a concomitant decrease in the translocation of $\mathrm{NF}-\kappa \mathrm{B}$ to the nucleus in the LPS-stimulated RAW264.7 cells.

NO acts as an initiator during inflammatory responses (21). It is produced by iNOS, and is an important mediator of acute and chronic inflammation (22), contributing to the pathogenesis of organ failure in circulatory shock (23). iNOS expression is stimulated by various mediators, including pro-inflammatory cytokines, such as IL-1 $\beta$, IL- 6 and TNF- $\alpha$, as well as bacterial products $(24,25)$. iNOS expression induces NO overproduction, resulting in the aggravation of inflammatory responses by activating cellular inflammatory signaling (26). Therefore, a decrease in the NO level through the inhibition of iNOS expression is considered a useful step in assessing the efficacy of novel therapeutics for the treatment of inflammatory diseases $(27,28)$. In the present study, RAME induced a significant decrease in the expression of pro-inflammatory cytokines, including IL-1 $\beta$, IL-6 and TNF- $\alpha$ in the LPS-stimulated RAW264.7 cells (Fig. 1B). RAME markedly decreased NO production in a concentration-dependent manner with a concomitant decrease in iNOS expression in the LPS-stimulated RAW264.7 cells. These findings indicate that RAME may effectively attenuate inflammatory responses through the inhibition of NO production caused by a decrease in iNOS and pro-inflammatory cytokines (Fig. 2).

LPS triggers several inflammatory reactions by binding to its specific receptor, Toll-like receptor 4 (TLR4), in various cells, including macrophages. During inflammatory responses, TLR4 is overexpressed, activated and induced by LPS, which induces an increase in COX-2 expression and $\mathrm{PGE}_{2}$ production (29). $\mathrm{PGE}_{2}$ is produced by a COX-2 product at inflammatory sites where it contributes to local increases in blood flow, edema formation and pain sensitization (30). The levels of COX-2 are elevated in a majority of colorectal carcinomas, and the aberrant expression of COX-2 leads to an increase in $\mathrm{PGE}_{2}$ production. COX-2 is an essential component for the LPS-induced activation of signaling pathways. Therefore, the suppression of COX-2 expression is important in controlling the inflammatory response. In the present study, RAME decreased the expression of COX-2 in the LPS-stimulated RAW264.7 cells, which eventually induced a significant decrease in $\mathrm{PGE}_{2}$ production (Fig. 3). These findings indicate that RAME has the potential to inhibit inflammatory responses.

$\mathrm{NF}-\kappa \mathrm{B}$ is an important factor that regulates the expression of inflammation-associated mediators, including iNOS, COX- 2 and TNF- $\alpha$, that contain NF- $\kappa \mathrm{B}$ binding motifs within their promoters. A number of anti-inflammatory agents exhibit their potency by suppressing $\mathrm{NF}-\kappa \mathrm{B}$ signaling $(31,32)$. The activation of $N F-\kappa B$ mainly occurs through the $\mathrm{I} \kappa \mathrm{B}$ 


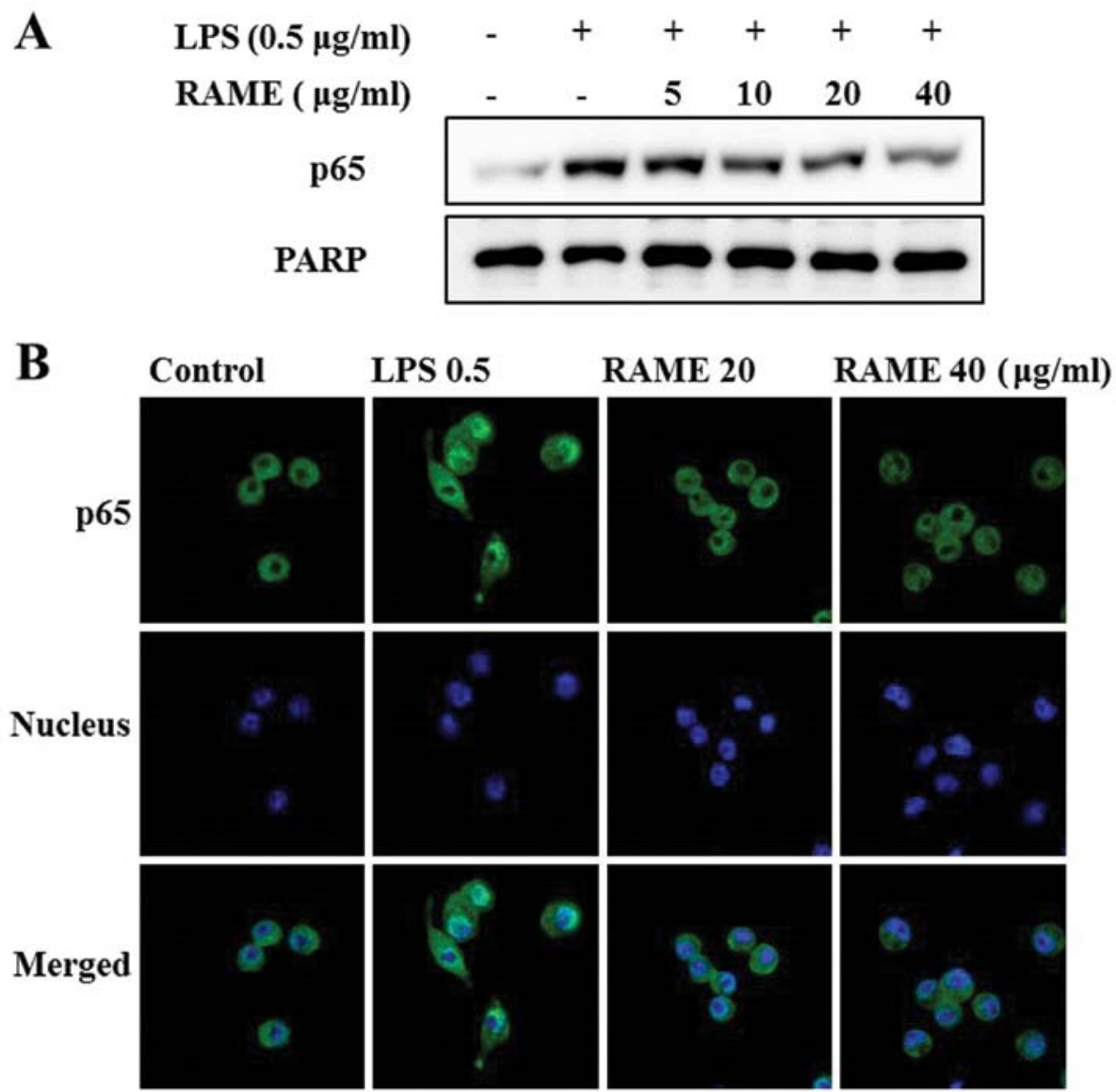

Figure 5. Inhibitory effects of Rhododendron album Blume methanol extract (RAME) on the nuclear translocation of nuclear factor- $\mathrm{kB}$ (NF- $\mathrm{kB}$ ). (A) The cells were pre-treated with increasing concentrations of $\operatorname{RAME}(5,10,20$ and $40 \mu \mathrm{g} / \mathrm{ml})$ for $1 \mathrm{~h}$ and then stimulated with lipopolysaccharide (LPS) (0.5 $\mu \mathrm{g} / \mathrm{ml})$ for $30 \mathrm{~min}$. The nuclear extracts were prepared for western blot analysis of NF-kB p65 in the nuclear fractions, as described in the Materials and methods. Poly(ADPribose) polymerase (PARP) was used as an internal control. (B) The cellular localization of NF- $\mathrm{\kappa B}$ was determined by immunocytochemistry. After fixation, the cells were stained with Alexa fluor 488 (green). The nuclei were visualized using DAPI (blue) and observed at x400 magnification. Control, untreated cells; LPS, LPS only $(0.5 \mu \mathrm{g} / \mathrm{ml})$; RAME, RAME plus LPS.

A

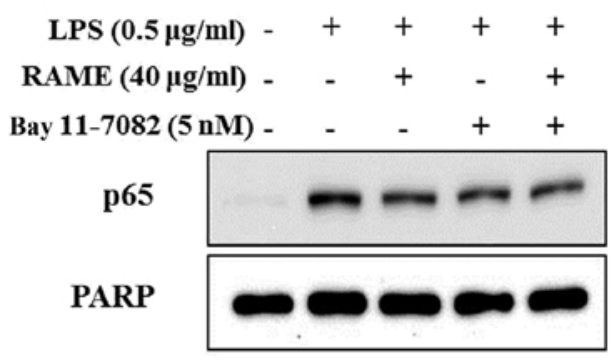

B

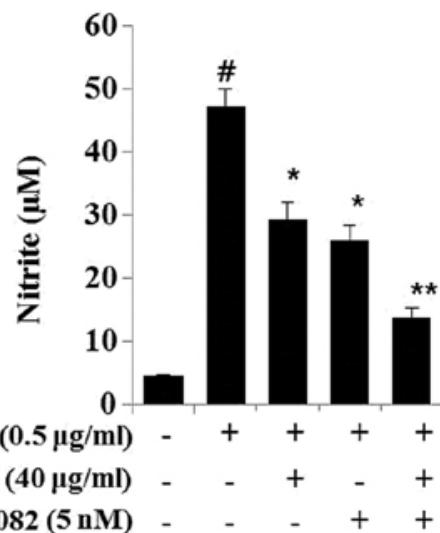

Figure 6. Inhibitory effects of Rhododendron album Blume methanol extract (RAME) and Bay 11-7082 on the nuclear translocation of nuclear factor- $\mathrm{kB}$ (NF- $\mathrm{kB}$ ) and the inhibition of nitric oxide (NO) expression. (A) RAW264.7 cells were pre-treated with increasing concentrations of RAME (40 $\mu \mathrm{g} / \mathrm{ml})$ and Bay 11-7082 for $1 \mathrm{~h}$ and then stimulated with lipopolysaccharide (LPS) $(0.5 \mu \mathrm{g} / \mathrm{ml})$ for $30 \mathrm{~min}$. The nuclear extracts were prepared for western blot analysis of NF- $\mathrm{kB}$ p65 in the nuclear fraction, as described in the Materials and methods. Poly(ADP-ribose) polymerase (PARP) was used as internal control. (B) RAW264.7 cells were pre-treated with RAME $(20 \mu \mathrm{g} / \mathrm{ml})$ and Bay $11-7082$ for $1 \mathrm{~h}$, and then stimulated with LPS $(0.5 \mu \mathrm{g} / \mathrm{ml})$. The NO concentrations were measured by Griess reaction. Three independent experiments were performed, and the data are presented as the means $\pm \mathrm{SEM}$. ${ }^{*} \mathrm{P}<0.05$ and ${ }^{* * *} \mathrm{P}<0.01$, compared with cells treated with LPS alone. ${ }^{\#} \mathrm{P}<0.001$ significantly different from normal control group.

kinase (IKK)-mediated phosphorylation of inhibitory mole-

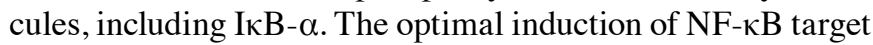

genes also requires the phosphorylation of NF- $\mathrm{KB}$ proteins, such as $\mathrm{p} 65$, within their transactivation domain by a variety 
of kinases in response to distinct stimuli (33). In particular, $\mathrm{NF}-\kappa \mathrm{B}$-targeted herbal remedies are considered to be more effective in treating inflammatory diseases, as they inhibit one or more activation steps in the signaling pathway (34). Therefore, in this study, we examined the effects of RAME on the phosphorylation of the nuclear translocation of the p65 subunit. Our results revealed that stimulation with LPS induced a decrease in p65 expression in the cytoplasm and an increase in its expression in the nucleus and that this effect was reversed by pre-treatment with RAME in a dose-dependent manner (Fig. 5). The present study demonstrated that RAME inhibited the LPS-induced NF- $\mathrm{B}$ activation by suppressing the phosphorylation of $\mathrm{NF}-\kappa \mathrm{B}$, as well as through its subsequent inhibotory effect on the nuclear translocation of $\mathrm{NF}-\kappa \mathrm{B}$, in RAW264.7 macrophages.

The MAPK pathway is one of the most ancient and evolutionarily conserved signaling pathways and plays essential regulatory roles in both innate and adaptive immune responses (35). MAPKs play an important role in the transcriptional regulation of the LPS-induced expression of iNOS and COX-2 (15). The LPS-induced production of cytokines in human monocytes involves several intracellular signaling pathways that include three MAPK pathways: the ERK 1/2, JNK and p38 pathways. It has been demonstrated that some active compounds inhibit LPS-induced inflammatory cytokine production through the downregulation of NF- $\kappa \mathrm{B}$ and MAPK activities in RAW264.7 cells (36). Thus, in this study, we investigated the effects of RAME on the activation of ERK1/2, JNK and p38 in LPS-stimulated cells. RAME significantly inhibited the phosphorylation of p38, ERK1/2 and JNK in the LPS-stimulated RAW264.7 cells (Fig. 4).

RAME exerts anti-inflammatory effects on RAW264.7 cells and macrophages; however, the detailed molecular mechanisms involved are unclear. RAME suppresses LPS-induced macrophage inflammatory responses through the blockade of NF- $\mathrm{BB}$. The detailed molecular mechanisms involve the inhibition of COX-2 and iNOS expression in RAW264.7 macrophages through the inactivation of NF- $\kappa \mathrm{B}$ by blocking the degradation of $\mathrm{I} \kappa \mathrm{B}$. Our data extend our understanding of the molecular mechanisms underlying the biological activities and pharmacological use of RAME. In addition, as demonstrated in this study, the inhibitor of I $\kappa$ B- $\alpha$ phosphorylation, Bay 11-7082, and RAME attenuated the activation of $N F-\kappa B$, thereby inhibiting the expression of NO (Fig. 6B). The aforementioned findings suggest that the ability to inhibit COX-2 and iNOS expression may partly account for the anti-inflammatory properties of RAME.

Our results revealed that RAME significantly suppressed the LPS-induced activation of $N F-\kappa B$. RAME inhibited the LPS-induced phosphorylation of p65, a critical step in significantly suppressing LPS-induced NF- $\kappa \mathrm{B}$ activation (37). LPS-induced p65 phosphorylation is required for p65 transcription activity $(38,39)$. RAME inhibited the production of $\mathrm{NO}$ and $\mathrm{PGE}_{2}$, and inhibited $\mathrm{NF}-\kappa \mathrm{B}$ and MAPK activation in the RAW264.7 cells.

In conclusion, the results from the present study indicate that RAME inhibits LPS-induced inflammatory responses. These effects were considered to be strongly associated with the suppression of $N F-\kappa B$ activation. Our data thus suggest that RAME may be an effective therapeutic agent for the treatment of inflammatory diseases.

\section{Acknowledgements}

The present study was supported by the grants from the Ministry of Science, ICT and Future Planning (FGC1011433) and from the Korea Research Institute of Bioscience and Biotechnology (KGM1221521) of the Republic of Korea.

\section{References}

1. Laskin DL and Pendino KJ: Macrophages and inflammatory mediators in tissue injury. Annu Rev Pharmacol Toxicol 35: 655-677, 1995.

2. Blank V, Hirsch E, Challis JR, Romero R and Lye SJ: Cytokine signaling, inflammation, innate immunity and preterm labour - a workshop report. Placenta 29 (Suppl A): S102-S104, 2008.

3. Weinberg JB, Misukonis MA, Shami PJ, et al: Human mononuclear phagocyte inducible nitric oxide synthase (iNOS): analysis of iNOS mRNA, iNOS protein, biopterin, and nitric oxide production by blood monocytes and peritoneal macrophages. Blood 86: 1184-1195, 1995.

4. Ricciotti E and FitzGerald GA: Prostaglandins and inflammation. Arterioscler Thromb Vasc Biol 31: 986-1000, 2011.

5. Grossman CJ, Wiseman J, Lucas FS, Trevethick MA and Birch PJ: Inhibition of constitutive and inducible cyclooxygenase activity in human platelets and mononuclear cells by NSAIDs and Cox 2 inhibitors. Inflamm Res 44: 253-257, 1995.

6. O'Neill GP, Kennedy BP, Mancini JA, et al: Selective inhibitors of COX-2. Agents Actions Suppl 46: 159-168, 1995.

7. Pouliot M, Baillargeon J, Lee JC, Cleland LG and James MJ: Inhibition of prostaglandin endoperoxide synthase-2 expression in stimulated human monocytes by inhibitors of p38 mitogen-activated protein kinase. J Immunol 158: 4930-4937, 1997.

8. Zhang G and Ghosh S: Toll-like receptor-mediated NF-kappaB activation: a phylogenetically conserved paradigm in innate immunity. J Clin Invest 107: 13-19, 2001.

9. Baeuerle PA and Baltimore D: I kappa B: a specific inhibitor of the NF-kappa B transcription factor. Science 242: 540-546, 1988.

10. Baker JR Jr and Baldwin JL: Allergy and immunology. JAMA 275: 1794-1795, 1996.

11. Ajizian SJ, English BK and Meals EA: Specific inhibitors of p38 and extracellular signal-regulated kinase mitogen-activated protein kinase pathways block inducible nitric oxide synthase and tumor necrosis factor accumulation in murine macrophages stimulated with lipopolysaccharide and interferon-gamma. J Infect Dis 179: 939-944, 1999.

12. Riches DW, Chan ED, Zahradka EA, Winston BW, Remigio LK and Lake FR: Cooperative signaling by tumor necrosis factor receptors CD120a (p55) and CD120b (p75) in the expression of nitric oxide and inducible nitric oxide synthase by mouse macrophages. J Biol Chem 273: 22800-22806, 1998.

13. Singer CA, Baker KJ, McCaffrey A, AuCoin DP, Dechert MA and Gerthoffer WT: p38 MAPK and NF-kappaB mediate COX-2 expression in human airway myocytes. Am J Physiol Lung Cell Mol Physiol 285: L1087-L1098, 2003.

14. Zheng X, Chang RL, Cui XX, Avila G, Huang MT, Liu Y, Kong AN, Rabson AB and Conney AH: Inhibition of NF- $\kappa$ B by (E)3-[(4-methylphenyl)-sulfonyl]-2-propenenitrile (BAY11-7082; BAY) is associated with enhanced 12- $O$-tetradecanoylphorbol13-acetate-induced growth suppression and apoptosis in human prostate cancer PC-3 cells. Int J Oncol 32: 257-264, 2008.

15. Guha M and Mackman N: LPS induction of gene expression in human monocytes. Cell Signal 13: 85-94, 2001.

16. Lawrence T, Willoughby DA and Gilroy DW: Anti-inflammatory lipid mediators and insights into the resolution of inflammation. Nat Rev Immunol 2: 787-795, 2002.

17. Mori N, Yamada Y, Ikeda S, et al: Bay 11-7082 inhibits transcription factor NF-kappaB and induces apoptosis of HTLV-I-infected T-cell lines and primary adult T-cell leukemia cells. Blood 100: 1828-1834, 2002

18. Hsiao WL and Liu L: The role of traditional Chinese herbal medicines in cancer therapy - from TCM theory to mechanistic insights. Planta Med 76: 1118-1131, 2010.

19. Ma HD, Deng YR, Tian Z and Lian ZX: Traditional Chinese medicine and immune regulation. Clin Rev Allergy Immunol 44: 229-241, 2013. 
20. Melillo B and Smith AB III: A unified synthetic strategy to the cryptocarya family of natural products exploiting anion relay chemistry (ARC). Org Lett 15: 2282-2285, 2013.

21. Porsti I and Paakkari I: Nitric oxide-based possibilities for pharmacotherapy. Ann Med 27: 407-420, 1995.

22. Kubes $P$ and McCafferty DM: Nitric oxide and intestinal inflammation. Am J Med 109: 150-158, 2000.

23. Southan GJ and Szabo C: Selective pharmacological inhibition of distinct nitric oxide synthase isoforms. Biochem Pharmacol 51: 383-394, 1996.

24. Taniguchi T: Regulation of cytokine gene expression. Annu Rev Immunol 6: 439-464, 1988.

25. Hughes TK, Kaspar TA and Coppenhaver DH: Synergy of antiviral actions of TNF and IFN-gamma: evidence for a major role of TNF-induced IFN-beta. Antiviral Res 10: 1-9, 1988.

26. Knott C, Stern G and Wilkin GP: Inflammatory regulators in Parkinson's disease: iNOS, lipocortin-1, and cyclooxygenases-1 and -2. Mol Cell Neurosci 16: 724-739, 2000.

27. Golde S, Coles A, Lindquist JA and Compston A: Decreased iNOS synthesis mediates dexamethasone-induced protection of neurons from inflammatory injury in vitro. Eur J Neurosci 18: 2527-2537, 2003.

28. Lee SH, Park SA, Ko SH, et al: Insulin resistance and inflammation may have an additional role in the link between cystatin $\mathrm{C}$ and cardiovascular disease in type 2 diabetes mellitus patients. Metabolism 59: 241-246, 2010.

29. Fukata M and Abreu MT: Role of Toll-like receptors in gastrointestinal malignancies. Oncogene 27: 234-243, 2008.

30. Giuliano $F$ and Warner TD: Origins of prostaglandin $E_{2}$ : involvements of cyclooxygenase (COX)- 1 and COX-2 in human and rat systems. J Pharmacol Exp Ther 303: 1001-1006, 2002.

31. Park JW, Kwon OK, Jang HY, et al: A leaf methanolic extract of Wercklea insignis attenuates the lipopolysaccharide-induced inflammatory response by blocking the NF-kappaB signaling pathway in RAW 264.7 macrophages. Inflammation 35: 321-331, 2012.
32. Connelly L, Palacios-Callender M, Ameixa C, Moncada S and Hobbs AJ: Biphasic regulation of NF-kappa B activity underlies the pro- and anti-inflammatory actions of nitric oxide. J Immunol 166: 3873-3881, 2001.

33. Viatour P, Merville MP, Bours V and Chariot A: Phosphorylation of NF-kappaB and IkappaB proteins: implications in cancer and inflammation. Trends Biochem Sci 30: 43-52, 2005.

34. Bylund J, MacDonald KL, Brown KL, et al: Enhanced inflammatory responses of chronic granulomatous disease leukocytes involve ROS-independent activation of NF-kappa B. Eur J Immunol 37: 1087-1096, 2007.

35. Zhang YL and Dong C: MAP kinases in immune responses. Cell Mol Immunol 2: 20-27, 2005.

36. Lee HS, Ryu DS, Lee GS and Lee DS: Anti-inflammatory effects of dichloromethane fraction from Orostachys japonicus in RAW 264.7 cells: suppression of NF-kappaB activation and MAPK signaling. J Ethnopharmacol 140: 271-276, 2012.

37. Hayden MS and Ghosh S: Signaling to NF-kappaB. Genes Dev 18: 2195-2224, 2004.

38. Sakurai H, Chiba H, Miyoshi H, Sugita T and Toriumi W: IkappaB kinases phosphorylate NF-kappaB p65 subunit on serine 536 in the transactivation domain. J Biol Chem 274: 30353-30356, 1999.

39. Kuprash DV, Udalova IA, Turetskaya RL, Rice NR and Nedospasov SA: Conserved kappa B element located downstream of the tumor necrosis factor alpha gene: distinct NF-kappa B binding pattern and enhancer activity in LPS activated murine macrophages. Oncogene 11: 97-106, 1995. 